\title{
Effect of Different Chemical Formulation on Agarwood (Aquilaria malaccensis) Resin Weight
}

\author{
Mohd Fauzi Elias', Azi Azeyanty Jamaludin², Adibah Abu Bakar², \\ Haniza Hanim Mohd Zain², Husni Ibrahim² \\ ${ }^{1}$ Perak Matriculation College, Kementerian Pendidikan Malaysia \\ ${ }^{2}$ Biology Department, Faculty of Science and Mathematics, Sultan Idris Education University, \\ Tanjong Malim, Perak, Malaysia \\ *Corresponding author: poji77mpk@gmail.com
}

DOI: https://doi.org/10.37134/ejsmt.vol7.2.1.2020

Received: 02 May 2020; Accepted: 01 July 2020; Published: 09 July 2020

Cite this article (APA): Elias, M. F., Jamaludin, A. A., Abu Bakar, A., Mohd Zain, H. H., \& Ibrahim, H. (2020). Effect of Different Chemical Formulation on Agarwood (Aquilaria malaccensis) Resin Weight. EDUCATUM Journal of Science, Mathematics and Technology, 7(2), 1-6. https://doi.org/10.37134/ejsmt.vol7.2.1.2020

\begin{abstract}
Agarwood is described as fragrance, smelling wood that is usually derived from the trunk of genus Aquilaria The objective of this study was to develop and evaluate four chemical-based inoculants to induce karas tree to form agarwood resin. Four chemical inoculants were applied into 6 years old karas tree (Aquilaria malaccensis) plantations in Slim River, Perak, Malaysia using dripping techniques. The inoculant used were labelled as A, B, C and D. Commercial inoculant was also used for comparison purposes and labelled as $\mathrm{K}$ while a healthy tree, act as control was labelled as N. After four months of inoculation, these samples were cut down and discoloured tissue samples were collected. Solvent extraction method using dichloromethane (DCM) was carried out to obtain the resin crude extract from plant tissues of the samples. All chemical formulation used were succesfully stimulated sample trees to produce resin. Inoculant B produced the highest crude extract recovery $(5.49 \%)$ compared to inoculant $\mathrm{C}$ (4.78\%) followed by A (4.32\%), D (2.98\%), K (1.07\%) and N (0.13\%). From this study, inoculant B showed the highest yield of resin. Hence, result from current study has the potential to contribute in enhancing new types of inoculant production for the agarwood industries in Malaysia.
\end{abstract}

Keywords: Agarwood, artificial inoculation, chemical inducement, Aquilaria malaccensis

\section{INTRODUCTION}

Agarwood is very popular substances around the world as it can be used with a variety of specific purposes, mainly for luxury fragrance, medicine, and beverages. It has been used to relieve kidney problems, abdominal pain, diarrhoea and lung diseases by the Chinese community from the past [1, 2]. Malaysian rainforests are said to be the oldest in the world, hosting a complex ecosystem with more than 50000 species of plants that survive in a diversity of habitats, including the Aquilaria species [3].

Aquilaria malaccensis belongs in Thymelaecea family that generates a secondary metabolic compound that has a fragrance smell [4]. It contains various genus which includes Aquilaria, Gyrinops and Wikstroemia that have long been known for its valuable resin. A. malaccensis is a species that had been commercially planted, but another species from the genus A. microcarpa, A. hirta, A. beccariana and A. rostrata can be found throughout Malaysian forests [4].

Nineteen indigenous species in Malaysia are capable of producing Agarwood. Thirteen species are in Peninsular Malaysia, eleven species in Sabah and another thirteen species in Sarawak [5]. These recorded species come from five genera that consist of seven Aquilaria species, six Gonystylus species, 
four Wikstroema species, one Aetoxylon and Enkleia species respectively. Nevertheless, A. malaccensis remains the most popular source of Agarwood among the other trees [5].

Agarwood is in high demand every year globally due to its various uses including for treating cancer and tumours which had caused the agarwood to increase in prices, depending on the quality grade [6]. In 2009, CITES had reported that Malaysia export permit of agarwood worth USD 14.85 million [7]. Whereas nowadays the highest quality grade of agarwood has reached up to USD 7894 per $\mathrm{kg}$, depending on the demand and the relevant consumer country [8]. Recently, the price had increased dramatically and it reaches up to USD 34210 per kg compared to the previous price of USD 5263 to USD 7894 per $\mathrm{kg}$ [9].

In a natural environment, healthy wood of karas tree appears as a white, soft and without scented resins. Usually, it has a softer wood core and light in colour. Agarwood is produced when the tree is injured (physically, biologically or chemically), and the injuries occurred had allowed the oxygen to enter the plant tissues and damaging the living cells [8]. As a result, trees will react to the process by producing resin extract in which the wood turned darker or dark red $[14,15]$ and contained aromatic compound such as agarwood [10]. The activation of the karas trees defence mechanism generally due to physical, biological and chemical injuries will result in the resin composting process [7]. The oleoresin that forms also is the result of the karas trees when they respond to another stimulation such as fungus infection, lightning strikes, fire and insect attacks.

It takes several year or decades for karas tree which still alive after wounding to form agarwood. There is no agarwood will be obtained from a healthy tree [16]. Scientists estimate that only $10 \%$ of the Aquilaria trees in the forest may contain agarwood. Under a natural condition, the resin is more commonly found in the tree of 20 years or older, with tree more than 50 years old reportedly having the highest concentration [2].

Various studies had been conducted by scientists and stakeholders in the agarwood industry to find inoculants that can cause the karas trees to produce a high-quality Agarwood resin in a short amount of time, in which the resulting resin quality will be equal or superior to the one that occurred naturally. High-grade agarwood usually contains aromatic compounds and terpene groups such as $\alpha$-guanine, $\beta$ selinene, aromadendrene, $\alpha$-bulnesene and agarospirol [8]. Thus far the best inoculants formulation of agarwood in karas tree remains unknown [11-13].

\section{MATERIALS AND METHODS}

\section{Study Site}

The study was conducted at Al Hilmi Agrofarm Plantation, Slim River, Malaysia. The karas trees were approximately 6 years old and the species were identified to be A. malaccensis. The voucher specimens of the species and its replicate were deposited at the herbarium of Universiti Pendidikan Sultan Idris for reference purposes. The voucher numbers listed as MFE001, MFE002 and MFE003.

\section{Chemical Treatments}

Inoculation formulations were produced using several selected chemicals based on Van Thanh \& Van Do, (2015) with several modifications. The formulations were prepared based on weight calculations per volume. A total of four different formulations were produced which were labelled as A, B, C and D. In comparison, one commercial inoculant that was bought from a private company (Gaharu Embun Sdn Bhd, Jerantut, Pahang, Malaysia) was used and labelled as K, and a healthy karas tree without any treatment was used for control (N). The control tree was not cut down but only the plant stem tissue was scrapped out for analysis. $80 \mathrm{ml}$ of each inoculant were kept in the reagent bottle before taken to the study area. 
Dripping technique was used during inoculation in the field. A hole with a diameter of $10 \mathrm{~mm}$ was bored on the tree using a 12-volt electric drill brand Mustang, from China. Only one hole was bored on each tree with as much as $80 \mathrm{ml}$ of inoculants per hole. Each type of inoculant was injected into two karas tree for replication purpose that resulted in 10 karas trees were used in total. The trees were left for 4 months before it was cut down.

\section{Crude Extraction}

Stem samples obtained were cut into smaller size before drying it in an oven at $50^{\circ} \mathrm{C}$ for 3 days and weighed afterwards. Dried samples were crushed and blended using a dry mill. The extraction process was done using solvent extraction (cold extraction techniques). A total of $50 \mathrm{~g}$ of stem samples were weighed for each inoculant. The stem samples of each inoculant were soaked in $500 \mathrm{ml} 95 \%$ dichloromethane (DCM) for nine days and replaced with a new solvent after three days. The solvent was filtrated and the filtration liquids were dried and made concentrated by using a rotary evaporator. The crude extract then weighed and stored in the freezer at $-4^{\circ} \mathrm{C}$ until further use.

\section{Statistical Analyses}

Data were analyzed using Statistical Package for Social Science 20.0 software. The result was then further analyzed using descriptive statistical (min), post-hoc Tukey and one-way ANOVA. All analyzed results are expressed in mean \pm SEM (standard error mean) with values considered significant when $p$ values are less than $0.05(p<0.05)$.

\section{RESULTS AND DISCUSSION}

Figure 1 shows the profile for Agarwood formation of karas tree after 4 months of inoculation. The observation showed that there are significant differences between each karas trees due to their response toward the chemical in which there were slightly different according to their colour and the thickness of the agarwood.
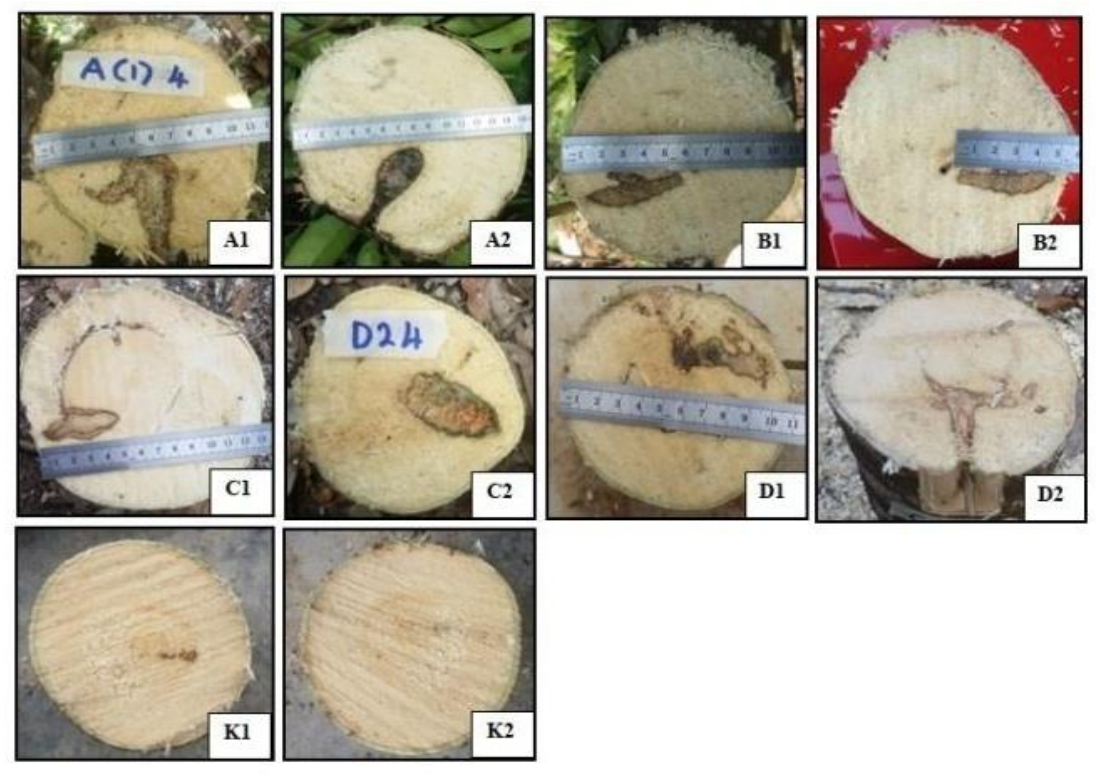

Figure 1: The trunk cross-sections treated with 4 types of Agarwood inoculants A-D and a commercial inoculants $K$ 
The cross-section of the trees treated with inoculants is shown in Figure 1. The entire trees were cut down after 4 months and showed developed resinous and dark area. The A1 and A2 referred to the same inoculants but at two different trees. However, $\mathrm{K} 1$ and $\mathrm{K} 2$ did not show any significant change in the wood area. According to the company's description, it should normally be used up to 2 to 3 litres of liquid for a single hole. In our study, we only used as much as $80 \mathrm{ml}$ of liquid. It is likely indicated that inoculant $\mathrm{K}$ is less effective when it is used in small quantities. Based on the result, it can be concluded that all of the karas trees responded to the inoculants stimuli to start producing agarwood resin. The tree labelled with A2 showed the darkest colour, followed by B1, B2, A1, D1, C2, D2, K1 and K2 respectively.

Table 1 and Figure 2 showed the weight of DCM crude extract obtained. Based on the table, it was found that inoculant B produced most resin amount, followed by inoculants C, A, D and K. Post-hoc Tukey's test indicated that inoculants A, B, C and D were significant $(\mathrm{p}<0.05)$ compared to other treatment.

Table 1. The 4-months crude extract using DCM

\begin{tabular}{lcc}
\hline Inoc & $\begin{array}{c}\text { Crude extract mean }(\mathbf{g}) \\
(\text { Mean } \pm \text { SEM) }\end{array}$ & Percentage (\%) \\
\hline A & $2.161 \pm 0.336^{*}$ & 4.32 \\
B & $2.734 \pm 0.078^{*}$ & 5.49 \\
D & $2.389 \pm 0.150^{*}$ & 4.78 \\
C & $1.492 \pm 0.341^{*}$ & 2.98 \\
K (commercial) & $0.536 \pm 0.053$ & 1.07 \\
N (control) & $0.065 \pm 0.034$ & 0.13 \\
\hline
\end{tabular}

*The mean difference is significant at $\mathrm{p}<0.05$

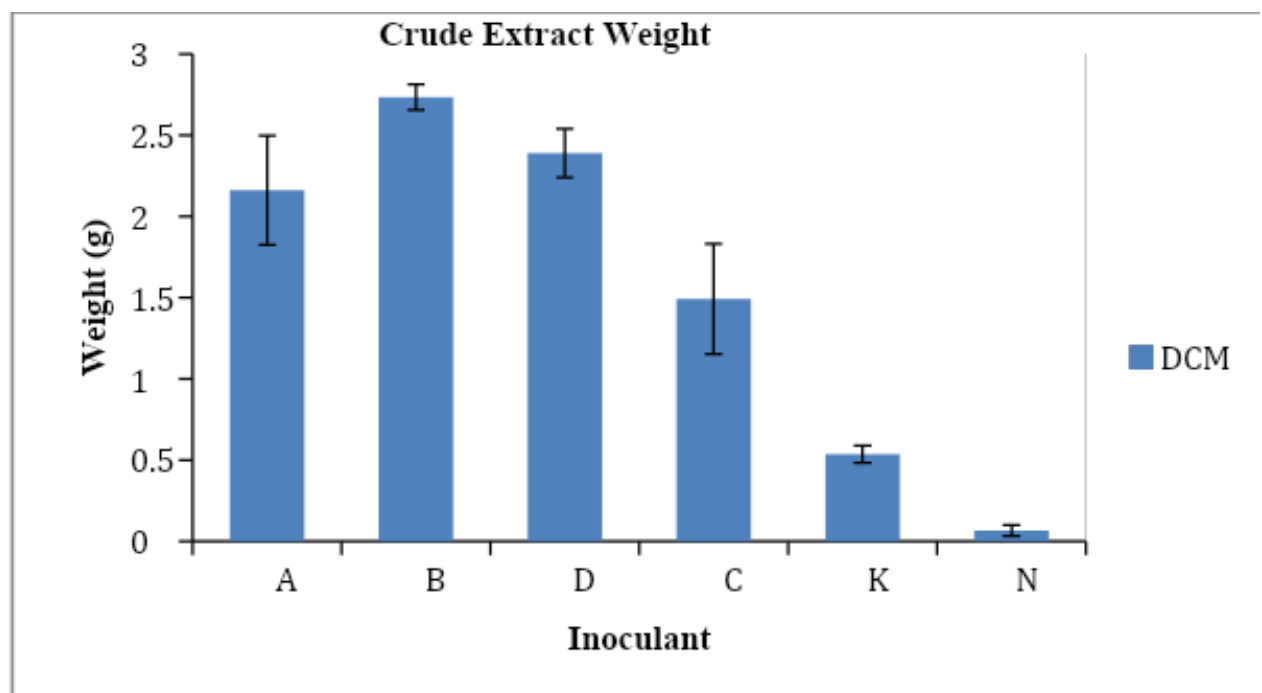

Figure 2: The crude extract resin recovery after 4-months inoculation. Results as mean $\pm \operatorname{SEM}(n=2)$

As shown in Table 1, the crude extract yield of agarwood obtained by inoculants $\mathrm{A}$ to $\mathrm{N}$ is ranging from $0.13 \%$ to $4.32 \%$. There is a significant difference in which the values were different from those of two control sample $(\mathrm{N})$ which is $0.065 \pm 0.034 \mathrm{~g}$. The result of the crude extract from the control trees showed that the healthy tree has a resin but in a very small amount. The higher weight oil recovery is inoculant $\mathrm{B}$. The highest weigh of resin are one of the indicators of inoculation effectiveness. The other indicators are the colour tissue changes, weigh of the resin and the chemical compounds present in the resin. The duration of 4 months is taken into account as it is expected to be appropriate based on the previous studies $[14,17,18]$. It is stated that the karas trees can produce resin as early as in the callus stage $[14,17,18]$. It is also found that within 3 months, karas trees has been shown to start producing resin if trees are treated with specific inoculants. From this result, A. malaccensis is probably more sensitive in inoculants B 
compared to the others. The difference between crude extract weight from different inoculants might be due to the different responses of the plant reacting to the chemical inducement ingredient and formulation. The plant defence system again pathogen attack or environmental stress will trigger the accumulation of resin [19].

The cold extraction executed using an organic solvent in determining total oil was found to be the best extraction method for some plant material that cannot tolerate the heated forms of extraction such as steam distillation. However, the problem with using solvents to get the crude extract is that in most of the time, residual solvents or impurities remains in the product [12]. The extraction yield is strongly dependent on solvent, thus the selection of extraction solvent is critical for the complex plant sample [20]. The extraction solvent system is generally selected based on the purpose of extraction, the polarity of interested compounds, the polarity of undesirable components, overall cost, safety and environmental concern $[21,22]$. The selection of DCM is suitable due to its bi-polarity properties and it suits for this experiment purposes. Most of the organic molecules are relatively non-polar and are usually soluble in an organic solvent but not in polar solvent like water [19]. Meanwhile, other researchers indicated chemical constituent and its contents in the same agarwood were different depending on the extraction method such as hydrodistillation, soaking using organic solvent, supercritical fluid carbon dioxide extraction and other relevant methods [22].

\section{CONCLUSION}

All formulations can stimulate the karas trees to produce resin. The karas trees react when the pain response was received by the tree tissue. This suggests that agarwood could be produced by artificially using chemical stimulation method. From the study, inoculants formulation A and B should be given further consideration as the formula produces more resin quantities compared to the other formulations. All the formulations have been reproduced to carry out a real-time study for a longer period for the determination of the effectiveness and chemical profile as well as determining the quality of the agarwood that was formed.

\section{REFERENCES}

[1] Suharti, S., Santosa, E., \& Turjama (2011) Feasibility Study of Business in Agarwood Inoculation and Different Stem Diameters and Inoculation Periods. J For Res,8(5),114-129

[2] Barden, A., Anak, N. A., Mulliken, T., \& Song, M. (2000) Heart of the Matter: Agarwood use and trade and CITES implementation for Aquilaria malaccensis, 1-52.

[3] Napis, S., Salleh, K. M., Itam, K., \& Latiff, A. (2001) Biodiversity Databases for Malaysian Flora and Fauna: An Update. In Proceedings of IWS2001 (Internet Workshop2001) (Vol. 21-23 Febr, p. 6).

[4] Zachary S. Rogers. (2009) A Revision of Malagasy Gnidia (Thymelaeaceae, Thymelaeoideae). Missouri Botanical Garden, 96(2), 324-369.

[5] Lok, E. (2016) Growth And Management of Aquilaria malaccensis For Agarwood.International Journal Of Agriculture, Forestry and Plantation, Vol.3 (Jun, 55-60.

[6] Lim, T. K. and Anak. N. A. (2010) Wood for trees: A review of the agarwood (gaharu) trade in Malaysia. TRAFFICSoutheast Asia.

[7] Yahya, A. (2011) Industri GAHARU Malaysia: Cabaran dan Prospek. (H. R. Husin,H.M. Atan, N. L. M. Halip, Hajah N. Hashim, Z. Hamid, S. B. Saleh, F. A. Bakar, Eds.) (2nd ed.). Lembaga Perindustrian Kayu Malaysia.

[8] Jayachandran, K., Sekar, I., Parthiban, K. T., Amirtham, D., \& Suresh, K. K. (2014) Analysis of different grades of Agarwood (Aquilaria malaccensis Lamk.) oil through GC-MS. Indian J Nat Prod Resour, 5(1), 44-47.

[9] Radhuan Hussain. (2014). Harga Gaharu RM130,000 /kg. Utusan Malaysia. Retrieved from https://www.utusan.com.my/berita/nasional/harga-gaharu-rm130-000-kg-1.24374.

[10] Yusof, S., Nizam, S., Mansor, R., Wei, P., \& Mazila, A. N. (2018) Gas Chromatography Analysis of Artificially Inoculated Agarwood Compounds Related to High Quality Agarwood from Malaysia Plantation. Chemistry of Advanced Materials, 3(3), 60-66. 
[11] Rasool, S., \& Mohamed, R (2016) Understanding Agarwood Formation and Its Challenges. In R. MOHAMED (Ed.), Agarwood: Science Behind the Fragrance (pp.39-56) Singapore: Springer Singapore. https://doi.org/10.1007/978-981-10-08337_3.

[12] Liu, Y., Chen, H., Yang, Y., Zhang, Z., Wei, J., Meng, H., Chen, H. (2013) Whole-tree agarwood-inducing technique:An efficient novel technique for producing high-qualityagarwood in cultivated Aquilaria sinensis trees. Molecules,18(3), 3086-3106.https://doi.org/10.3390/molecules18033086.

[13] Zhang, X. L., Liu, Y. Y., Wei, J. H., Yang, Y., Zhang, Z., Huang, J. Q., Liu, Y. J. (2012) Production of highQuality agarwood in Aquilaria sinensis trees via whole-tree agarwood-induction technology. Chin. Chem. Lett. (Vol. 23).

[14] Okudera, Y., \& Ito, M (2009) Production of agarwood fragrant constituents in Aquilaria calli and cell suspension cultures. Plant Biotechnology, 26(3), 307-315.

[15] Chen, H., Yang, Y., Xue, J., Wei, J., Zhang, Z., \& Chen, H. (2011) Comparison of Compositions and Antimicrobial Activities of Essential Oils from Chemically Stimulated Agarwood, Wild Agarwood and Healthy Aquilaria sinensis (Lour.) Gilg Trees. Molecules, 16(6), 4884. https://doi.org/10.3390/molecules16064884.

[16] Chua, L. S. L. (2008) Agarwood (Aquilaria malaccensis) in Malaysia. NDF Workshop Case Studies(Vol. 3).

[18] Zhang, Z., Wei, J., Han, X., Liang, L., Yang, Y., Meng, H., Gao, Z. (2014) The sesquiterpene biosynthesis and vessel-occlusion formation in stems of Aquilaria sinensis (lour.) trees induced by wounding treatments without variation of microbial communities. International Journal of Molecular Sciences, 15(12), 2358923603.https://doi.org/10.3390/ijms151223589.

[19] Lee, N Y, MAC Yunus, Z Idham, MSH Ruslan, A. A. and N. I. (2017). Agarwood excraction.pdf. In Second International Conference on Chemical Engineering (ICCE) UNPAR (p. 162).

[20] Peng, C. S., Osman, M. F., Bahari, N., Nuri, E. A., Zakaria, R., \& Rahim, K. A. (2015). Agarwood inducement tech- chong.pdf. J Agrobiotech, 6.

[21] Van Thanh, L., \& Van Do, T. (2015). Impacts of biological, chemical and mechanical treatments on sesquiterpene content in stems of planted Aquilaria crassna tree. Agroforestry Systems, 89, 973-981. https://doi.org/10.1007/s10457-015-9829-3

[22] Wang, J., Sun, B., Cao, Y., Tian, Y., \& Li, X. (2008). Optimisation of ultrasound-assisted extraction of phenolic compounds from wheat bran. Food Chemistry. https://doi.org/10.1016/j.foodchem.2007.06.062. 